\title{
Avaliação da política de cotas da UEPG: desvelando o direito à igualdade e à diferença
}

\author{
Andreliza Cristina de Souza \\ Mary Ângela Teixeira Brandalise
}

Resumo: Este trabalho resulta de uma dissertação de mestrado que realizou uma avaliação da política de cotas da Universidade Estadual de Ponta Grossa (UEPG) referente ao período de 2007 a 2010. Objetivou-se realizar uma avaliação da efetividade da política quanto ao favorecimento da ampliação do acesso ao ensino superior para estudantes negros oriundos de escolas públicas e estudantes oriundos de escolas públicas. Os instrumentos de coleta de dados foram a entrevista e o questionário. Para análise dos dados utilizou-se a metodologia do Discurso do Sujeito Coletivo, que possibilitou a construção dos discursos- síntese, resultado dos depoimentos dos sujeitos participantes da pesquisa. À luz do referencial teórico, os documentos institucionais e os dados empíricos foram analisados e permitiram conhecer como foi o processo de implantação da política. Embora a tentativa de reprodução das desigualdades seja percebida e confirmada dentro da instituição, há a existência do movimento de superação das desigualdades sociais e educacionais pelo viés da educação. Este trabalho permite afirmar que a política de cotas da UEPG, em alguns aspectos, é efetiva, no entanto, em outros aspectos, a política merece atenção por parte de seus implementadores. A política de cotas da UEPG tem vigência de oitos anos e esta avaliação, realizada durante o seu período de vigência, confirma a importância do acompanhamento da implementação de políticas públicas como instrumento necessário para o exercício da democracia.

Palavras-chave: Política de cotas. Avaliação de política pública. Discurso do sujeito coletivo.

\section{Evaluation of the policy quotas of UEPG: unveiling the Right to equality and difference}

Abstract: This work results from a dissertation that conducted an evaluation of the quota policy of the State University of Ponta Grossa (UEPG) for the period 2007 to 2010. The objective was to verify of the effectiveness of the quota policy regarding favoring the expansion of access to university for black students from public schools and students from public schools. The instruments chosen for the collection of empirical data were interviews and questionnaires. The methodology of the Collective Subject Discourse was used, which enabled the construction of summary discourses, resulted from the reports of subjects in the research. Although the attempted reproduction of inequalities is perceived and confirmed within the institution, the movement to overcome the social and educational inequalities by the views of education exists. The research allows us to affirm that the policy of quota in UEPG is effective in some aspects. In other aspects, the policy deserves attention from its implementers. The quota policy of UEPG is valid for eight years and this evaluation, performed during its lifetime, confirm the importance of monitoring the implementation of public policies as a necessary instrument for the exercise of democracy.

Key words: Quota policy. Public policies evaluation. Collective subject discourse. 


\section{Introdução}

Discussões têm sido travadas atualmente sobre políticas públicas para a educação, e as ações afirmativas para acesso ao ensino superior estão no alvo de estudos com os mais diferentes enfoques. Foi nesse contexto que surgiu a presente investigação que tem por objetivo principal avaliar a efetividade da política de cotas quanto ao favorecimento da ampliação do acesso ao ensino superior para estudantes negros oriundos de escolas de escolas públicas e estudantes oriundos de escolas públicas, implantada na Universidade Estadual de Ponta Grossa - UEPG em 2006. O trabalho desenvolvido contribui para maiores reflexões acerca do papel do Estado na democratização do acesso e permanência no ensino superior no Brasil, possibilitando também a expansão das pesquisas relacionadas às políticas públicas afirmativas para a educação.

O artigo aqui apresentado está organizado em 4 partes, sendo que a primeira discute a reprodução das desigualdades existentes no sistema educacional, com base na teoria da violência simbólica de Bourdieu (2010a; 2010b; 2010c; 2010d; BOURDIEU; PASSERON, 2008). Também são contempladas questões sobre política pública, política afirmativa e seus pressupostos básicos: democracia, igualdade e justiça social. $\mathrm{Na}$ segunda parte as discussões predominam no campo da avaliação e avaliação de políticas públicas, que são permeadas pelos estudos de Dias Sobrinho (2003) e de Arretche (2001; 2003; 2007), sendo que a avaliação da política de cotas nesta investigação é abordada sociologicamente, segundo as proposições de Afonso (2009). Num terceiro momento, apresenta-se a análise dos dados obtidos através dos depoimentos dos sujeitos pesquisados segundo a metodologia do Discurso do Sujeito Coletivo, proposto por Lefèvre, Lefèvre e Teixeira (2000). O trabalho finaliza com as considerações finais sobre a avaliação realizada e seus resultados.

\section{Políticas públicas para acesso ao ensino superior: a relevância da política de cotas para redução das desigualdades}

A pesquisa que originou este texto foi realizada em um momento histórico marcado pelo conflito e pela polêmica que as políticas de ação afirmativa, e o sistema de cotas em especial, têm gerado na sociedade. As muitas discussões travadas no campo político e educacional têm tomado corpo sob novas perspectivas diante do tema em questão. A presente temática se mostra de elevada importância quando se fala em igualdade de oportunidades e igualdade de resultados no ensino superior, questão muito presente na atualidade. 
Bourdieu afirma que ao longo da história a população tem acreditado no poder da educação para a mobilidade social, esperando que a ascensão do indivíduo (social e economicamente) se dê através da elevação do grau de estudo. Para o autor o sistema de ensino age para a perpetuação das diferenças entre classes, mostrando que os estudantes que obtém os melhores resultados fazem parte das classes que ocupam os mais altos lugares na pirâmide social e econômica.

Embora no Brasil existam políticas públicas que buscam ampliar o acesso e permanência de estudantes de classes desfavorecidas, é fato que os maiores beneficiados pelas políticas públicas educacionais no ensino superior são os dominantes em sua classe. Contudo, sem a possibilidade dessas políticas, muitos destes sujeitos também não teriam chance no ensino superior público brasileiro. Fica claro, assim, que as classes com maior capital econômico são as que possuem um grau também mais alto de capital cultural, e, logo, maior possibilidade para o acesso ao ensino superior.

Nesse sentido, para o autor embora a escola seja um instrumento de manutenção social, ela transmite uma noção diferenciada, dissimulando seu papel, de forma que sua função de transmissora de cultura e de agente fundamental para o desenvolvimento social e humano é assimilada pela sociedade em geral. Esta afirmação demonstra a ideologia embutida por detrás do sistema educacional, que, segundo Bourdieu (2010d, p. 10) “[...] servem interesses particulares que tendem a apresentar como interesses universais", que é o papel da ideologia capitalista e neoliberal.

O sistema de ensino serve como sistema de reprodução das desigualdades existentes e as legitima, garantindo às classes superiores a perpetuação de seus privilégios. As classes superiores mantêm seus privilégios culturais sem precisar intervir diretamente no sistema, afirmando que o ideal democrático (neoliberal) está sendo mantido, pois todos têm acesso à educação, todos têm as mesmas oportunidades.

Esta análise social realizada por Bourdieu é muito válida para explicar as relações de produção e reprodução, pois torna possível a compreensão de que o sistema educacional, com sua tradição meritocrática, exclui grande parcela de estudantes provindos de classes sociais mais baixas. Contudo, é necessário ir além para que seja possível compreender a totalidade da dinâmica das relações sociais.

Atualmente surge uma reação à reprodução das desigualdades e à exclusão sofrida pelos estudantes oriundos de escola pública no sistema de ensino superior: as políticas públicas voltadas à redução das desigualdades, as políticas afirmativas. 
A política de cotas é um tema que vem sendo bastante estudado nos últimos anos, nos âmbitos nacional e internacional. Souza (2006) diz que para melhor compreender uma área de conhecimento, sua origem e ontologia, é necessário entender sua trajetória, e não é diferente com as políticas públicas.

A política de cotas é uma política que visa, em caráter provisório, a criação de incentivos a grupos desfavorecidos para beneficiar os alunos que provêm de camadas populares, com baixo poder econômico, geralmente oriundos de escolas públicas, ou minorias étnicas. Nesse sentido, considera-se essencial vislumbrar conceitos básicos que permeiam as políticas afirmativas, uma vez que, para alguns estudantes esta política está garantindo a igualdade real no tocante ao acesso ao ensino superior.

Para Maliska (2009) a política de cotas se legitima se ela estiver alcançando a finalidade esperada, ou seja, reduzindo as desigualdades e proporcionando ao grupo beneficiado melhores condições de vida. Autores como Brandão (2005), Queiroz (2004), Feres Junior e Zoninsen (2006), Jensen (2010), Duarte e Bertúlio (2009) comprovam em seus estudos que tais políticas, mesmo que ainda sejam incipientes, têm favorecido a elevação dos índices de ingresso de classes historicamente desfavorecidas nas universidades. Zoninsein (2006) atenta para a importância de existirem programas de avaliação e acompanhamento das políticas de cotas para propiciar a permanência com qualidade dos estudantes cotistas no ensino superior.

Nesse contexto, é essencial compreender as relações entre o sistema governamental, suas implicações nos processos educacionais e os resultados que serão gerados na vida das pessoas. Esta é uma forma de desvelar o sentido das políticas educacionais adotadas sob uma perspectiva de superação das desigualdades e de transformação da sociedade.

Estado e política são conceitos inseparáveis, diante disso, a discussão sobre política implica em discussões sobre o Estado e as formas de governo nele imbricadas. Para Shiroma, Moraes e Evangelista (2006, p. 7) "o pensamento político moderno tende a definir Estado como o momento supremo da vida coletiva dos seres humanos". O Estado contemporâneo em suas diferentes concepções tem diferenças marcantes no tocante ao sistema político, que pode assumir conceitos sob diferentes perspectivas.

O sistema vivenciado atualmente, o neoliberalismo, amplia as desigualdades existentes, pois as classes diferentes não podem concorrer igualmente, exatamente por não serem iguais. Neste contexto, estudantes oriundos de classes historicamente desfavorecidas não podem concorrer com estudantes que tiveram melhores oportunidades educacionais e sociais, devido à violên- 
cia simbólica e a reprodução das desigualdades vivida por sua classe. Daí a importância de que políticas de caráter afirmativo, como a política de cotas, seja adotada, numa perspectiva de superação das desigualdades sociais e educacionais, para diminuir o fosso existente entre pobres e ricos, brancos e negros, homens e mulheres.

O neoliberalismo defende que oferecer oportunidades diferenciadas a grupos diferenciados fere o princípio da igualdade e da liberdade, mesmo quando os grupos beneficiados são grupos com oportunidades minoradas em virtude de sua posição social. "[...] a maximização da liberdade está em proteger-se o sistema de mercado, necessário e suficiente para a existência da liberdade individual" (PERONI, 2003, p. 27). Dessa forma é essencial que o mercado seja protegido do Estado e da opressão que as classes mais baixas podem oferecer ao desfrutarem de políticas públicas voltadas para superação das desigualdades.

Estas são razões para que a política de cotas seja rechaçada pela parcela mais abastada da sociedade, ou, ao contrário, pelas próprias classes desfavorecidas que são contra as políticas afirmativas, nesse caso quando há o desconhecimento das relações sociais, sendo que as próprias classes de baixa renda legitimam o discurso da igualdade pela força da ideologia do mérito para todos os cidadãos, independentemente da classe à qual pertencem.

A política de cotas está ampliando o acesso de estudantes de classes desfavorecidas ao ensino superior. Nesse sentido, considera-se essencial vislumbrar conceitos básicos que permeiam as políticas afirmativas, uma vez que, para alguns estudantes esta política está garantindo a igualdade real no tocante ao acesso ao ensino superior. Assim sendo, para que uma política pública tenha caráter afirmativo, é necessário que ela contemple pressupostos como democracia, igualdade e justiça social.

Importante ressaltar que as discussões travadas sobre democracia política ao longo dos séculos envolveu, principalmente, um paralelo entre as duas doutrinas políticas dominantes: o liberalismo e o socialismo. Dessa forma, pode-se afirmar que a democracia se acomoda a doutrinas com conteúdos ideológicos diversos, pois "certamente nenhum regime histórico jamais observou inteiramente o ditado de todas estas regras; e por isso é lícito falar de regimes mais ou menos democráticos" (BOBBIO; MATTEUCCI; PASQUINO, 2010, p. 327).

A política de cotas pode ser considerada uma política democrática, já que facilita a socialização de um bem (o ensino superior) para quem não tem chances iguais para concorrer a esse nível de ensino. No entanto, a democratização do acesso ao ensino superior é apenas um instrumento para se atingir a democracia plena. 
É necessário mais que democratização do acesso. É necessário igualdade. Em se tratando de política de cotas é fundamental garantir o direito a igualdade e direito à diferença.

Bobbio (2000, p. 10) diz que quando se afirma que todos são iguais é necessário especificar outras questões, como "[...] com que entes estamos tratando e com relação a que são iguais, ou seja, é preciso responder a duas perguntas: a) igualdade entre quem?; e b) igualdade em quê?". Para Winch e Gingell (2007) o conceito de igualdade está intimamente associado ao conceito de justiça, e uma vez que uma das preocupações da educação é a justiça, igualdade e educação estão intimamente ligadas.

Piovesan (2005, p. 47) afirma que "ao lado do direito à igualdade, surge também, como direito fundamental, o direito à diferença". Para a autora é fundamental que o respeito à diferença e à diversidade, assegurem um tratamento especial às classes desfavorecidas, como por exemplo, os alunos beneficiários da política cotas nas universidades públicas. A autora afirma ser insuficiente o tratamento destinado hoje a essas classes, de forma genérica e abstrata e enfatiza a necessidade de que estes sujeitos sejam vistos em sua particularidade.

Nesse contexto, ressalta-se a importância da igualdade das condições de acesso e de permanência com qualidade no ensino superior, pois "se a democracia confunde-se com a igualdade, a implementação do direito à igualdade, por sua vez, impõe tanto o desafio de eliminar toda e qualquer forma de discriminação como o desafio de promover a igualdade" (PIOVESAN, 2005, p. 52).

As políticas afirmativas visam reparar a exclusão socioeconômica. Reparação, justiça distributiva e diversidade são argumentos básicos para a justificação das políticas de ação afirmativa. Elas devem propiciar a diversificação de culturas e proporcionar uma maior representatividade aos grupos minoritários.

Esse tipo de política, apesar de estar longe de acabar com a discriminação racial e social, diminui o fosso existente entre brancos e negros, ricos e pobres. É necessário entender as políticas de ação afirmativa como políticas de inclusão e não de exclusão social, e em defesa do multiculturalismo. As ações afirmativas podem ou não contribuir para a diminuição da discriminação, mas o mais importante é que com elas são reconhecidas as diferenças raciais e desigualdades de classe e a necessidade de sua superação.

\section{Avaliação: pressupostos filosóficos e epistemológicos}

Para compreender um processo avaliativo, no entanto, é primordial entender seus fundamentos enquanto ciência (aspectos filosóficos) e enquanto campo de 
produção de conhecimento (aspectos epistemológicos). Avaliar é conhecer um objeto, uma realidade ou um sujeito. Avaliar é atribuir valor a algo, apontar suas características positivas e negativas, de forma a sugerir correções necessárias com vistas à sua melhoria (ARRETCHE, 2007; FIGUEIREDO; FIGUEIREDO, 1986; TREVISAN; VAN BELLEN, 2008; FAGUNDES; MOURA, 2009).

Grande parte da literatura sobre a avaliação está voltada para a aprendizagem do aluno e boa parte trata sobre técnicas avaliativas. No entanto, a avaliação não trata somente do ensino e não se reduz somente às técnicas, mas possibilita o reconhecimento das fragilidades existentes, permitindo uma retomada dos objetivos iniciais e novas definições no processo de gestão, pois a avaliação pode dar impulso às mudanças.

Leite (2005) explica que é impossível realizar um ato avaliativo sem considerar pressupostos de ordem filosófica e as concepções de homem, de mundo e de sociedade que acompanham este ato. A avaliação constitui-se como um termo histórico e social, desde sua origem até suas diversas aplicações, pois toda postura avaliativa adotada, cada enfoque, representa o tipo de sociedade que ela quer servir.

Dias Sobrinho (2003) mostra que a avaliação se assume como uma política, possuidora de sentido ético, com interesse público e argumenta que, com o crescimento do campo da avaliação, principalmente no que tange à sua complexidade e inserção nos campos político e social, ficam claras as contradições existentes, principalmente quando essas contradições não são meramente epistemológicas, mas que resultam de distintas concepções de mundo.

Para Gadotti (2005) a avaliação é por natureza uma questão política, pois seria ingênuo acreditar na avaliação somente enquanto processo técnico. Fernandes (2010) alerta que a avaliação não é um ato neutro, uma vez que sendo prática social carrega consigo questões éticas, políticas e sociais.

Dias Sobrinho (2003) contribui, destacando que uma vez que ela produz efeitos, não é inocente e não promove resultados absolutos e inquestionáveis, que não se pode escolher qualquer avaliação afirmando ser indiferente fazê-la ou não. "Se a avaliação fosse isenta de valores, fosse mero instrumento técnico, não produziria contradições e, portanto, não se transformaria em campo de disputas acirradas - o que, aliás, ocorre com qualquer ação ou fato social" (p. 92).

Vale ressaltar que a avaliação muitas vezes pode ser utilizada como um mecanismo, ligada a outros mais, com fim de obter, manter ou ampliar a hegemonia. Popkewitz (1992) é categórico ao afirmar que a avaliação é uma estratégia do Estado, agindo como parte da produção das ideias de um determinado campo 
social. Para ele estudar as estratégias avaliativas exige a compreensão dos complexos processos de produção e relações de poder.

Desafios teórico-metodológicos da avaliação de políticas educacionais evidenciam as permanentes transformações neste campo, que também sofre influências de acontecimentos nos níveis global, nacional e local (MUNHOZ, 2006), da redefinição dos quadros identitários (culturais, étnicos etc.) existente nos contextos políticos e sociais (ESTEBAN; AFONSO, 2010).

Considerando a relação direta da avaliação com os processos sociais e de mudança social, Afonso (2009) sugere que, essa relação, pode ser objeto de estudo da sociologia da avaliação, inserida na sociologia da educação. Lüdke e Mediano (1994) explica que até recentemente a avaliação não havia recebido um tratamento dentro de uma perspectiva sociológica, o que, segundo a autora, pode permitir a produção de um conhecimento mais adequado sobre os mecanismos delicados que a avaliação envolve.

Afonso (2009) lembra que a constituição de um campo específico para se pensar a avaliação não implica na constituição de outra sociologia, separada da sociologia da educação, mas que este novo espaço surge com o objetivo de dar visibilidade à avaliação no interior da sociologia da educação.

Nessa perspectiva, caberá, então, à sociologia da avaliação discutir

[...] a relação da avaliação com os processos de mudança social (mas também organizacional), bem como discutir a sua utilização enquanto suporte a processos de legitimação política e de regulação/desregulação, verificáveis em diferentes níveis societais e institucionais (AFONSO, 2009, p. 17).

A sociologia da avaliação pode contemplar então as discussões aos níveis micro, meso e macro do sistema educativo.

Ao contemplar a avaliação enquanto construção social e compreendendo-a numa perspectiva sociológica torna-se importante considerar sua prática social ao longo da história. É fundamental, para o estudo sociológico da avaliação, compreender sua trajetória e evolução, como requisitos essenciais nas pesquisas em avaliação e para a avaliação de políticas públicas de maneira consciente e fundamentada.

Dias Sobrinho (2003) explica que os avaliadores precisam expressar sensibilidade e capacidade de resposta ao que interessa aos destinatários, o que reclama procedimentos metodológicos adaptados às necessidades de cada caso. $\mathrm{O}$ autor lembra que este enfoque é defendido também por MacDonald, que o chama de avaliação democrática, pois reconhece o pluralismo de valores e que 
representa um conjunto de interesses. Este enfoque parte do princípio de que a participação de todos os envolvidos é fundamental, pois "não se trata de um processo tranquilo e sem contradições" (p. 35).

Para a melhoria e aperfeiçoamento de políticas, programas, projetos ou serviços é fundamental a participação ativa dos envolvidos, valorizando os processos de autoavaliação combinados com as avaliações externas. As avaliações, nessa perspectiva, requerem a relação entre os sujeitos, baseadas em princípios de responsabilidade, na experiência desses sujeitos concretos e nos processos de socialização.

A avaliação de políticas públicas ocorre fortemente ancorada em um conjunto de valores, ideologia e concepções políticas partilhadas pelos avaliadores, o que caracteriza um processo avaliativo dentro de um sistema político. Draibe (2001) defende que as pesquisas em avaliação propiciam novas direções e correções de políticas públicas. Para que este fim se efetive, Arretche (2007) explica que os instrumentos de análise e avaliação devem ser adequados, pois os resultados da avaliação de uma política ou de um programa não devem ser confundidos com as opções pessoais do pesquisador.

O estudo e avaliação de políticas públicas permite observar a importância deste campo teórico acadêmico. Percebe-se, a necessidade em se compreender o papel do Estado e da avaliação de políticas para melhoria das condições sociais e educacionais dos cidadãos, com vistas a sua participação ativa na sociedade.

Como uma avaliação de política pública tem sua tônica na melhoria da política para todos os envolvidos, enfatiza-se a necessidade do movimento dialético entre a teoria e a realidade analisada para a produção de resultados efetivos. O interesse em contribuir para a compreensão da implementação e dos caminhos traçados durante a vida de uma política é fundamental para se desvelar os resultados e impactos da política junto aos sujeitos envolvidos e por ela afetados. Por esse motivo este trabalho analisa a efetividade da política de cotas da UEPG com vistas a possibilitar a reflexão e superação de suas fragilidades, considerando que este movimento caracteriza o fenômeno avaliativo dentro de uma postura crítica e dialética.

\section{Avaliação da política de cotas da UEPG}

No Estado do Paraná, as IES que primeiramente decidiram implantar a política de cotas foram a Universidade Estadual de Londrina (UEL) em 2004 e a Universidade Federal do Paraná (UFPR). Na UEPG as discussões oficiais foram iniciadas no ano de 2005, com uma proposta de reserva de vagas nos 
processos seletivos de vestibular para candidatos oriundos de escolas públicas e também para aqueles oriundos de escolas públicas que se autodeclarassem negros.

Para realização da pesquisa foram realizados questionários com acadêmicos ingressantes pela política de cotas, além de entrevistas com os gestores envolvidos no processo de implantação da política na UEPG. Optou-se por envolver, primeiramente, os estudantes ingressantes pelo sistema de cotas na instituição, com objetivo de coletar informações sobre a política, sua abrangência e efetividade. Num segundo momento foram realizadas as entrevistas com os gestores universitários que presenciaram e estiveram envolvidos diretamente com o processo de implantação da política de cotas na UEPG.

Tanto os depoimentos obtidos por meio dos questionários como os dados das entrevistas foram analisados à luz da metodologia do Discurso do Sujeito Coletivo - DSC (LEFÈVRE; LEFÈVRE, 2005a), o que permitiu conhecer a percepção dos envolvidos sobre a política de cotas em estudo. A análise dos dados traz informações relevantes sobre a política avaliada e ao mesmo tempo possibilita que ela seja repensada e ajustada.

A metodologia que mais se adequou para a análise dos dados da pesquisa foi a Metodologia do Discurso do Sujeito Coletivo - DSC, proposta por Lefèvre e Lefèvre (2005a), porque essa proposta metodológica sinaliza a presença de um sujeito individual do discurso, mas também expressa uma referência coletiva, na medida em que esse 'eu' individual representa uma coletividade. Segundo Lefèvre e Lefèvre (2005a) se o pensamento de um indivíduo considerado isoladamente é um discurso, então o pensamento da coletividade desses indivíduos também deveria ser considerado um discurso.

Esta proposta de análise de dados em pesquisa qualitativa utiliza três figuras metodológicas. A primeira delas é a ancoragem (AC). Os autores afirmam que quase todos os discursos proferidos têm uma ancoragem e que este está alicerçado em teorias, pressupostos, conceitos e hipóteses e manifesta uma expressão linguística que o autor do discurso professa, baseada em teorias ou ideologias pessoais. A segunda figura metodológica é a ideia central (IC), que pode ser entendida como a afirmação que permite exprimir o sentido essencial do conteúdo discursivo mencionado pelo indivíduo em seu depoimento, e também nos depoimentos dos diferentes indivíduos, que apresentem sentido semelhante ou complementar. Os autores fazem ainda uma importante ressalva, dizendo que a ideia-central não é "[...] uma interpretação, mas uma descrição do sentido de um depoimento ou de um conjunto de depoimentos" (LEFÈVRE; LEFÈVRE, 2005b, p. 17, grifo no original). 
Os autores afirmam que os DSC são construídos com a essência da terceira figura de linguagem, as expressões-chave (ECH). Estas são "[...] constituídas por transcrições literais de parte dos depoimentos" e permitem que o pesquisador, resgate a essência do conteúdo discursivo que, em geral, representa as respostas às questões de pesquisa (LEFÈVRE; LEFÈVRE; TEIXEIRA, 2000, p. 18). O DSC consiste na análise do material verbal coletado na pesquisa, extraindo-se dos depoimentos pessoais as ideias-centrais e suas correspondentes expressões-chave, para posterior composição de um ou vários discursos-síntese.

Os questionários foram aplicados para turmas de terceira e quarta séries de onze cursos de graduação da instituição. Como se buscou obter os depoimentos dos estudantes cotistas, foi fundamental selecionar os cursos que, além de possuírem grande número de estudantes ingressantes pela política de cotas, possuíssem outras características peculiares, tais como: cursos com condições específicas, como cursos integrais, historicamente elitistas, com maior concorrência nos concursos vestibulares e, em contrapartida, cursos noturnos com a maioria de alunos trabalhadores.

O questionário foi composto por 10 (dez) questões, sendo queasrespostas foram analisadas segundo a metodologia do DSC. A análise dessas questões foi realizada segundo as etapas dos procedimentos metodológicos propostas por Lefèvre e Lefèvre (2005a; 2005b): tabulação dos dados, construção dos discursos e apresentação dos resultados ${ }^{1}$. No processo de coleta de dados foram obtidos cento e sessenta e seis questionários respondidos por estudantes cotistas.

Inicialmente as respostas das questões foram analisadas isoladamente, a partir do depoimento integral dos acadêmicos; o segundo passo constituiu-se de identificar e sublinhar em cada uma das respostas das questões as expressões-chave (ECH) que originaram as Ideias-Centrais (IC). Identificadas as IC's, estas foram agrupadas e codificadas para cada questão, da seguinte forma:

- IC2: onde "IC" representa a Ideia-Central oriunda da questão proposta; " 2 " representa o número da questão.

- IC2 $2_{\mathrm{A} \text { : }}$ onde "IC" representa a Ideia-Central da questão; "2" representa o número da questão analisada; e "A" representa a subcategoria contida na Ideia-Central.

1 As questões de número 1 e 9 não foram analisadas segundo a metodologia do DSC. A questão de número um solicitava ao estudante a forma de ingresso no ensino superior, e sua tabulação foi quantitativa, permitindo a identificação dos estudantes negros oriundos de escola pública e estudantes oriundos de escola pública. Na questão de número nove "Há outros aspectos que você deseja comentar sobre a sua forma de ingresso na UEPG?" apenas 44 dos 166 estudantes participantes realizaram comentários, razão pela qual ela não foi analisada. 
No quadro 1 é possível visualizar as IC's originárias dos depoimentos dos acadêmicos cotistas às questões do questionário.

\section{Quadro 1 - Descrição das IC's identificadas no questionário de pesquisa}

\begin{tabular}{|lcl|}
\hline \multicolumn{1}{|c|}{ Ideia-Central (IC) } & Codificação \\
\hline $\begin{array}{l}\text { Adaptação dos estudantes ingressantes pela política de cotas no ensino } \\
\text { superior }\end{array}$ & IC2 \\
\hline $\begin{array}{l}\text { Posicionamento dos estudantes cotistas quanto à política de cotas para o } \\
\text { ensino superior }\end{array}$ & IC3 \\
\hline $\begin{array}{l}\text { Ações que favorecem a permanência do estudante cotista no ensino superior } \\
\text { Sugestões de ações que favoreçam a permanência do estudante cotista no } \\
\text { ensino superior }\end{array}$ & IC4 \\
\hline \begin{tabular}{l} 
Democratização do acesso ao Ensino Superior através da política de cotas \\
\hline Promoção da justiça social através da política de cotas
\end{tabular} & IC6 \\
\hline $\begin{array}{l}\text { Promoção da igualdade através da política de cotas } \\
\text { Ingresso no ensino superior: com ou sem a política de cotas }\end{array}$ & IC8 \\
\hline
\end{tabular}

Já no quadro 2 é possível visualizar as IC's originárias das entrevistas com os gestores envolvidos no processo de implantação e implementação da política de cotas na UEPG.

\section{Quadro 2 - Descrição das IC's identificadas nas entrevistas}

\begin{tabular}{|lc|}
\hline \multicolumn{1}{|c|}{ Ideia-Central (IC) } & Codificação \\
\hline Implantação da política de cotas & IC1 \\
\hline $\begin{array}{ll}\text { Ações de acompanhamento do estudante cotista } \\
\text { Democratização do acesso ao ensino superior, promoção da justiça social e } \\
\text { redução das desigualdades }\end{array}$ & IC2 \\
\hline
\end{tabular}

As informações desveladas no processo de avaliação da política de cotas da UEPG possibilitam afirmar que de fato uma política tem 'vida': nasce, cresce, se desenvolve. Nos discursos do sujeito coletivo dos estudantes e gestores fica evidente como a implementação da política vem ocorrendo institucionalmente. $\mathrm{Na}$ análise dos discursos foi possível perceber o grau de efetividade da política implementada, com suas potencialidades e fragilidades. 


\section{0 processo avaliativo: desvelando a realidade ${ }^{2}$}

A seguir é possível visualizar alguns discursos obtidos com a pesquisa. Os DSC's que seguem foram selecionados por terem sido compostos pela maioria dos sujeitos pesquisados.

\section{Adaptação dos estudantes ingressantes pela política de cotas no ensino su- perior}

- Estudantes cotistas que tiveram uma adaptação satisfatória no ensino superior:

Encontrei algumas dificuldades no começo. Houve o estranhamento natural de quem acabou de sair do Ensino Médio e teve contato com outra realidade. A dificuldade encontrada em um curso superior é muito superior à enfrentada no Ensino Médio, principalmente na rede pública, pois é tudo diferente, você torna-se responsável por si mesmo. Houve um pouco de dificuldade pelo excessivo número de textos que devem ser lidos, pois quando fiz Ensino Médio não eram cobradas muitas leituras. Mesmo com o interesse que demonstro pelas disciplinas e pelo esforço em aprender o conteúdo, a princípio a metodologia de ensino foi um pouco "pesada", mais pela questão de que em colégio público não havia uma cobrança tão grande para com nossas responsabilidades. Acredito que o fato de estudar em uma escola pública no Ensino Médio dificultou muito meu desempenho de início, sinto dificuldades devido a uma antiga falha em minha base curricular. No Ensino Médio estamos adaptados a estudar pouco e já na universidade precisamos estudar bastante e também não trabalhamos com muitos prazos, eles são bem flexíveis, já na graduação estes prazos tem de ser cumpridos. Porém, consegui me adaptar bem com o tempo, compreendi a metodologia de ensino, pois aprendemos cada coisa em sua hora para que possamos ter o conhecimento e compreensão do todo, ou seja, construímos dia a dia o nosso conhecimento.

Estudantes cotistas favoráveis e contrários à política de cotas

- Estudantes favoráveis à política de cotas devido à diferença da qualidade entre o ensino público e o privado.

2 Neste artigo serão apresentados apenas alguns discursos construídos na realização da pesquisa. Para aprofundamento consultar a dissertação de mestrado de Andreliza Cristina de Souza (2012). 
Sou completamente favorável, não posso ser contra a algo que participo, pois sou cotista. Sou a favor enquanto medida provisória, devido à desigualdade de qualidade de ensino público comparado com o privado. Principalmente pela questão de que alunos da rede privada possuem um ensino de mais qualidade e contam com auxílio de cursinhos ou aulas particulares. Já os demais não tem acesso a uma preparação adequada para frequentar uma universidade. É uma forma de dar oportunidades a pessoas que não tiveram um ensino particular, que hoje tem mais peso do que o público, no que diz respeito ao ensino médio. No meu caso sempre fui uma das melhores da sala no colégio público, sempre estudei por conta própria, mas ainda assim não tinha o preparo que os alunos de colégio particular receberam, e a política de cotas me ajudou muito. Sei que não sou menos inteligente que meus colegas que vieram do colégio particular. Penso que a política de cotas é o mínimo que o governo pode fazer para recompensar a defasagem na educação pública. Ela seria desnecessária se a educação pública fosse melhorada.

\section{Política de cotas como instrumento de democratização do acesso ao ensino superior}

- Estudantes que acreditam que a política de cotas da UEPG democratiza o acesso ao ensino superior.

A democratização é evidente, pois se olharmos vinte anos atrás a universidade pública era 99\% branca, o que tem mudado devido à implementação do sistema de cotas. Ajuda nos cursos mais concorridos, fazendo uma concorrência mais justa. Agora a universidade pública não é mais um lugar apenas para as classes mais favorecidas, a inclusão no ensino superior aumentou as chances de grande parte da população de estudar, o que é direito de todo cidadão. As cotas abrem um enorme acesso da população de baixa renda, pessoas com o mesmo nivel de conhecimento concorrem entre si. A maior parte dos estudantes pobres não faz vestibular e muitos não tem chances suficientes para entrar e se adaptar. Dentro da universidade podemos encontrar diferentes pessoas com diversas opiniões e ideais diferentes, várias experiências, sendo estes oriundos de escolas públicas ou particulares. 


\section{Ações institucionais para permanência do estudante cotista no ensino superior}

- Estudantes que desconhecem ou julgam não existir ações que favorecem a permanência do estudante na instituição.

Enquanto acadêmico não conheço nenhum tipo de ação, nunca ouvi falar, não visualizo nenhuma ação específica neste sentido. Para não ser injusto com a instituição, se ela oferece eu desconheço, não tem chegado até nós, mas seria muito interessante se tivesse. Não vejo trabalho diferenciado algum para algum eventual aluno cotista com dificuldade para acompanhar o curso. Desde que ingressei na UEPG não notei nenhuma diferença de tratamento entre cotistas e não cotistas, nem mesmo para verificar o desempenho dos cotistas e incentivá-los a continuar, caso houvesse dificuldades. Fui tratado como os outros. Não percebo nenhum tipo de política para evitar a evasão. Uma vez assisti a uma palestra que demonstrava os resultados de pesquisas realizadas, que o indice de reprovação e desistência entre os alunos cotistas era menor do que o índice dos alunos da cota universal. Talvez o panorama mude se houver uma maior integração do calouro com as atividades extra-curso ou então algum tipo de incentivo ao estudante. Até hoje não percebi nada com relação a isso.

\section{Política de cotas como instrumento de promoção da igualdade}

- Estudantes que acreditam que a política de cotas não promove a justiça social e/ou corrige as desigualdades sociais e étnicas.

As cotas minimizam essas diferenças, mas não as eliminam. Muitas ações são apenas "pano de fundo". A política de cotas para mim é um modo do governo mostrar que se importa com os marginalizados, mas é dificil através de uma "ajudinha" romper com anos de injustiças sociais e étnicas. A única forma de corrigir seria não haver necessidade de cotas, pois apesar de entrar na faculdade o aluno continua pobre. Também acho que pelo fato dos demais estudantes estarem desinformados sobre o assunto, isto gera uma polêmica maior. Esse tema vai muito, além disso, envolve culturas e a particularidade de cada comunidade ou indivíduo, mas isso com o tempo está melhorando e os estudantes estão se conscientizando. 
- Estudantes afirmam que a política de cotas não promove a igualdade entre os cidadãos.

"Igualdade" é um termo muito forte. Promover a igualdade entre os cidadãos não passa apenas pelo mero acesso das cotas. Ela dá mais chances a quem não teve um ensino melhor, de fazer universidade, de ter ensino superior, promove igualdade na concorrência, ex: alunos oriundos de escola pública competem com os que tiveram o mesmo nível de escolaridade e alunos oriundos de escola particular competem com alunos de mesmo nível de escolaridade, embora as porcentagens de vagas para cada "categoria" não sejam iguais, poderia ser um nível adequado de vagas para cotistas. Acho que tem muita coisa bem mais importante que se pode ser feito. Ela possibilita uma abrangência maior de acesso ao ensino superior, mas não garante uma sociedade mais igualitária. Só a política de cotas sozinha não promove a igualdade, depende de outras politicas sociais de promoção da igualdade e principalmente o fim do preconceito. Mais fatores precisam caminhar nesse sentido. A política de cotas proporciona uma oportunidade, mas para promover efetivamente essa igualdade social, mais oportunidades em outros horizontes precisam acontecer.

\section{Acesso ao ensino superior com a política de cotas}

- Estudantes cotistas que teriam sido aprovados no ensino superior da UEPG sem a política de cotas.

Acredito que para o curso que eu fiz sim, pois consegui uma boa colocação no vestibular. A pontuação que obtive foi mais que suficiente. Sem as cotas seria um dos resultados medianos, mas também poderia ter passado com o método universal. A política de cotas apenas me ajudou a ficar mais fácil a entrada na universidade, esta foi uma opção que eu fiz. A prova da UEPG não é difícil, então eu passaria com facilidade, pois o ponto de corte é o mesmo. Acredito que as cotas melhoraram muito para os alunos menos favorecidos como a mim. Reconheço que sem as cotas diminui e muito as chances de alunos de instituição pública (escola) ingressar no ensino superior. Existem muitos que só estão aqui devido a essa política, isto é real. A possibilidade de entrar com o sistema de cotas acaba ajudando muito, pois possibilita uma concorrência mais justa com relação a escolas particulares. 
Pode-se afirmar que há efetividade da política avaliada, ainda que esta seja parcial, relativa. Mas, certamente a política de cotas tem favorecido a ampliação do acesso ao ensino superior ao longo dos seus quatro anos de implantação. Contudo, é inevitável destacar que a violência simbólica sofrida pelos estudantes ao longo dos anos de Educação Básica é percebida no ensino superior, e que tanto gestores quanto os próprios estudantes cotistas tentam reproduzir as desigualdades sociais na universidade.

Neste estudo de caso, que priorizou a realização de uma avaliação qualitativa, ficou demonstrado que ao mesmo tempo em que há a tentativa de reprodução das desigualdades sociais, há a tentativa da superação dessas relações desiguais. Quanto mais são acentuadas e elevadas as desigualdades, mais ocorre o movimento contrário, e a superação ganha espaço possibilitando transformações na realidade social, ainda que muito pequenas.

\section{Considerações finais}

Alguns aspectos da política de cotas da UEPG podem ser destacados com a conclusão desta pesquisa. Percebeu-se que a participação nos debates iniciais para implantação da política de cotas teve um índice muito pequeno de participação. Caracterizou como um processo que enfrentou muita resistência interna na ocasião de sua adoção. Importante ressaltar que a política de cotas para estudantes negros encontra resistência em todos os níveis e instâncias institucionais.

No decorrer deste trabalho alguns estudantes negros oriundos de escola pública relatam que sofrem discriminação, inclusive vindo de professores. Embora o relato de discriminação com estudantes cotistas tenha aparecido também nos relatórios da Comissão, não foram encontrados relatos de ações ou momentos promovidos pela Comissão em que o tema possa ser debatido para redução da discriminação e do preconceito. Considera-se esta como uma atribuição da institucional, uma vez que existe uma comissão responsável por acompanhar a política. Compreende-se como acompanhamento oferecer condições para que a política de cotas seja efetiva, ou seja, que proporcione aos estudantes condições de igualdade no ingresso e após ele.

Observou-se ainda que esta é uma política pouco discutida após sua implantação na comunidade universitária. Os debates foram realizados com o intuito de implantar a política, contudo, compreende-se que a discussão não deve cessar principalmente para aqueles estudantes que ingressam anualmente na instituição e que não participaram as discussões iniciais. 
Destaca-se que apenas o acompanhamento de notas é feito pela Comissão, e embora este modelo de acompanhamento ocorra, não foram criadas estratégias para que as dificuldades que são diagnosticadas sejam sanadas. Há o relato de alguns estudantes que encontraram dificuldade de adaptação devido à defasagem de conteúdos, e mesmo para estes estudantes não foram pensadas estratégias que possam auxiliá-los. É positivo que o estudante cotista seja tratado de maneira igualitária dentro da universidade, mas é importante lembrar que este não é igual aos demais. Ele ingressou por um sistema diferenciado, merece um acompanhamento diferenciado. Os estudantes revelam que não existe a estrutura necessária para atender as necessidades dos estudantes cotistas. É necessário que seja criada uma estrutura para que as necessidades imediatas dos estudantes sejam sanadas.

As médias obtidas pelos acadêmicos durante o curso de graduação não tem grandes diferenças entre as três cotas existentes na UEPG. Isso demonstra que o estudante se sente excluído dos processos de seleção, mas consegue se inserir e responder às exigências da vida acadêmica de forma positiva. Os dados mostram que de 2007 a 2009 o número de matriculados vem aumentando na UEPG, com destaque para a cota de escola pública. Já o abandono, a desistência e o trancamento vêm diminuindo consideravelmente ano após ano, em todas as cotas.

Destaca-se que esta pesquisa possibilitou observar diversos pontos positivos, sendo que $85 \%$ dos estudantes cotistas tiveram uma adaptação satisfatória no ensino superior, confirmando os dados obtidos nos relatórios elaborados pela Comissão. Ainda $85 \%$ dos estudantes são favoráveis à política de cotas, sendo que $45,5 \%$ deles são favoráveis devido à diferença da qualidade entre o ensino público e o privado.

Dos estudantes entrevistados $75 \%$ acreditam que a política de cotas da UEPG democratiza o acesso ao ensino superior. Os gestores também consideram que a política de cotas tem democratizado o acesso ao ensino superior às classes historicamente excluídas e discriminadas.

Entretanto, o presente trabalho também permitiu encontrar dados que merecem atenção por parte de seus implementadores, sendo que 44,4\% dos estudantes desconhecem ou julgam não existir ações que favorecem a permanência do estudante na instituição. Este é um dado muito preocupante, pois para estes estudantes a UEPG não está oferecendo condições satisfatórias à sua permanência no ensino superior. Dos sujeitos participantes da pesquisa $34 \%$ dos estudantes sugerem como ação, que poderia favorecer a permanên- 
cia no ensino superior, maiores investimentos na estrutura organizacional da instituição. Os acadêmicos indicam que professores comprometidos, incentivo à pesquisa, expansão dos programas de bolsas, laboratórios bem equipados, adequação curricular, atendimento adequado ao acadêmico, promoção de eventos científicos, entre outros, são fatores que favorecem a permanência de um estudante no ensino superior.

$51 \%$ dos estudantes acreditam que a política de cotas não promove a justiça social e/ou corrige as desigualdades sociais e étnicas. Os gestores entrevistados compartilham desta afirmação, pelo fato de que as cotas não promovem a justiça social sozinha, sendo necessárias outras ações concomitantemente. Ainda 50,6\% dos estudantes acreditam que a política de cotas não promove a igualdade entre os cidadãos. Os gestores entrevistados confirmam os discursos dos estudantes, pois para eles a política de cotas não tem o poder de promover a igualdade, mas de contribuir para este processo.

$49 \%$ dos estudantes cotistas declararam que teriam sido aprovados no ensino superior da UEPG sem a política de cotas. Este dado oferece pontos fundamentais a serem discutidos. Estes estudantes em especial não precisariam da política de cotas para ingressar no ensino superior, logo, a política de cotas está beneficiando um público que não necessita desse tipo de auxílio. No entanto é imprescindível descobrir porque a política de cotas da UEPG está com este caráter: um motivo pode ser o fato de a política de cotas estar beneficiando as elites das classes, que tem condições de pagar por uma preparação pré-vestibular; outra possibilidade é que em função da elevação da nota de corte, a preparação entre os candidatos vem sendo cada vez mais acentuada nos vestibulares.

A avaliação da política não teve como pretensão decidir pelo sucesso ou fracasso da política de cotas. Ao contrário, buscou investigar as potencialidades e fragilidades da política durante parte de seu período de vigência e contribuir para que as fragilidades observadas possam ser corrigidas ainda nos quatro anos restantes de sua vigência.

Espera-se que esta pesquisa sobre a avaliação contribua para a melhoria das condições de ingresso e permanência de estudantes negros oriundos de escola pública e de estudantes oriundos de escola pública, para a criação de projetos institucionais que favoreçam a permanência dos estudantes no ensino superior, para o desenvolvimento de novas pesquisas acadêmicas sobre as políticas afirmativas e que desencadeie reflexões e discussões sobre a necessidade de se garantir a todo cidadão o direito à igualdade e o direito à diferença. 


\section{Referências}

AFONSO, A. J. Avaliação educacional: regulação e emancipação. São Paulo: Cortez, 2009.

ARRETCHE, M. T. S. Uma contribuição para fazermos avaliações menos ingênuas. In: BARREIRA, M. C. R. N.; CARVALHO, M. C. B. Tendências e perspectivas na avaliação de políticas e programas sociais. São Paulo: IEE/PUC-SP, 2001. p. 43-56.

ARRETCHE, M. T. S. Dossiê agenda de pesquisa em políticas públicas. Revista Brasileira de Ciências Sociais, São Paulo, v. 18, n. 51, fev. 2003.

ARRETCHE, M. T. S. Tendências no estudo sobre avaliação. In: RICO, E. M. Avaliação de políticas sociais: uma questão em debate. São Paulo: Cortez, 2007. p. 29-39

BOBBIO, N. Igualdade e liberdade. Rio de Janeiro: Ediouro, 2000.

BOBBIO, N.; MATTEUCCI, N.; PASQUINO, G. Dicionário de política. Brasilia: Ed. UnB, 2010.

BOURDIEU, P. A escola conservadora: as desigualdades frente à escola e à cultura. In: NOGUEIRA, M. A.; CATANI, A. Escritos de educação. Petrópolis: Vozes, 2010a. p. 39-64.

BOURDIEU, P. O capital social - notas provisórias. In: NOGUEIRA, M. A.; CATANI, A. Escritos de educação. Petrópolis: Vozes, 2010b. p. 65-69.

BOURDIEU, P. Os três estados do capital cultural. In: NOGUEIRA, M. A.; CATANI, A. Escritos de educação. Petrópolis: Vozes, 2010c. p. 71-79.

BOURDIEU, P. O poder simbólico. Rio de Janeiro: Bertrand Brasil, 2010d. BOURDIEU, P.; PASSERON, J. C. A reprodução: elementos para uma teoria do sistema de ensino. Petrópolis: Vozes, 2008.

BRANDÃO, C. D. F. As cotas na universidade pública brasileira: será esse o caminho? Campinas: Autores Associados, 2005.

DIAS SOBRINHO, J. Avaliação: políticas educacionais e reformas da educação superior. São Paulo: Cortez, 2003. 
DRAIBE, S. M. Avaliação de implementação: esboço de uma metodologia de trabalho em políticas públicas. In: BARREIRA, C. R. N.; CARVALHO, M. C. B. Tendências e perspectivas na avaliação de políticas e programas sociais. São Paulo: IEE/PUC-SP, 2001. p. 13-42.

DUARTE, E. C. P.; BERTÚLIO, D. L. D. L. Cotas raciais no ensino superior: entre o jurídico e o político. Curitiba: Juruá, 2009.

ESTEBAN, M. T.; AFONSO, A. J. Avaliação: reconfigurações e sentidos na construção de um campo. In: ESTEBAN, M. T.; JANELA, A. J. Olhares e interfaces: reflexões críticas sobre a avaliação. São Paulo: Cortez, 2010. p. 9-14.

FAGUNDES, H.; MOURA, A. B. D. Avaliação fde programas e políticas públicas. Textos \& Contextos, Porto Alegre, v. 8, n. 1, p. 89-103, jan./jun. 2009.

FERES JUNIOR, J.; ZONINSEIN, J. Ação Afirmativa e universidade: experiências nacionais comparadas. Brasília: UnB, 2006.

FERNANDES, D. Acerca da articulação de perspectivas e da construção teórica em avaliação educacional. In: ESTEBAN, M. T.; AFONSO, A. J. Olhares e interfaces: reflexões críticas sobre a avaliação. São Paulo: Cortez, 2010. p. 15-44.

FIGUEIREDO, M. F.; FIGUEIREDO, A. M. C. Avaliação política e avaliação de políticas: um quadro de referência teórica. Análise \& Conjuntura, Belo Horizonte, v. 1, n. 3, p. 107-127, set./dez. 1986. GADOTTI, M. Concepção dialética da avaliação. In: DEMO, P. Avaliação qualitativa. Campinas: Autores Associados, 2005. p. ix-xiv

JENSEN, G. Políticas de cotas raciais em universidades brasileiras: entre a legitimidade e a eficácia. Curitiba: Juruá, 2010.

LEFÈVRE, F.; LEFÈVRE, A. M. C. Depoimentos e discursos: uma proposta de análise em pesquisa social. Brasília: Liber Livro, 2005a.

LEFÈVRE, F.; LEFÈVRE, A. M. C. O discurso do sujeito coletivo: um novo enfoque em pesquisa qualitativa (desdobramentos). Caxias do Sul: Educs, 2005b. 
LEFÈVRE, F.; LEFÈVRE, A. M. C.; TEIXEIRA, J. J. V. O discurso do sujeito coletivo: uma nova abordagem metodológica em pesquisa qualitativa. Caxias do Sul: EDUCS, 2000.

LEITE, D. Reformas universitárias: avaliação institucional participativa. Petrópolis: Vozes, 2005.

LÜDKE, M.; MEDIANO, Z. Avaliação na escola de $\mathbf{1}^{\mathbf{0}}$ grau: uma análise sociológica. Campinas: Papirus, 1994.

MALISKA, M. A. Análise da constitucionalidade das cotas para negros em universidades públicas. In: DUARTE, E. C. P.; SILVA, P. V. B.; BERTÚLIO, D. L. L. Cotas raciais no ensino superior: entre o jurídico e o político. Curitiba: Juruá, 2009. p. 57-74.

MUNHOZ, D. E. N. Entre a universalidade da teoria e a singularidade dos fenômenos: enfrentando o desafio de conhecer a realidade. Emancipação, Ponta Grossa, v. 6, n. 1, p. 25-40, 2006.

PERONI, V. M. V. Política educacional e papel do Estado: no Brasil dos anos 1990. São Paulo: Xamã, 2003.

PIOVESAN, F. Ações afirmativas da perspectiva dos direitos humanos. Cadernos de Pesquisa, São Paulo, v. 35, n. 124, p. 43-55, jan./abr 2005.

POPKEWITZ, T. Algunos problemas y problemáticas en la producción de la evaluación. Revista de Educación, Madri, n. 299, p. 95-118, 1992.

QUEIROZ, D. M. Universidade e desigualdade: brancos e negros no ensino superior. Brasília: Liber Livro, 2004.

SHIROMA, E. O.; MORAES, M. C. M. D.; EVANGELISTA, O. Política educacional. Rio de Janeiro: DP\&A, 2006.

SOUZA, A. C. Avaliação da política de cotas da UEPG: desvelando o direito à igualdade e à diferença. 2012. 248 f. Dissertação (Mestrado em Educação) - Universidade Estadual de Ponta Grossa, Ponta Grossa, 2012.

SOUZA, C. Políticas públicas: uma revisão de literatura. Sociologias, Porto Alegre, v. ano 8, n. 16, p. 20-45, jul./dez. 2006.

TREVISAN, A. P.; VAN BELLEN, H. M. Avaliação de políticas públicas: 
uma revisão teórica de um campo em construção. Revista de Administração Pública, Rio de Janeiro, v. 42, n. 3, p. 529-550, maio/jun. 2008.

WINCH, C.; GINGELL, J. Dicionário de filosofia da educação. São Paulo: Contexto, 2007.

ZONINSEIN, J. Minorias étnicas e a economia política do desenvolvimento: um novo papel para universidades públicas como gerenciadoras da ação afirmativa no Brasil? In: FERES JUNIOR, J.; ZONINSEIN, J. Ação Afirmativa e universidade: experiências nacionais comparadas. Brasília: UnB, 2006. p. 63-78.

Andreliza Cristina de Souza - Universidade Federal de São Carlos São Carlos | SP | Brasil. Contato: andrelizacsouza@gmail.com

Mary Ângela Teixeira Brandalise - Universidade Estadual de Ponta Grossa Ponta Grossa | PR | Brasil. Contato: marybrandalise@uol.com.br Artigo recebido em 25 de janeiro de 2013 e aprovado em 10 de abril de 2013. 
